\title{
Towards a strategy for project management implementation
}

\author{
Chris J. Brown \\ Graduate School of Business, University of Stellenbosch. P.O. Box 610. Bellville 7535. South Africa
}

Received May 1999

\begin{abstract}
The basic tenet of this article is that the implementation of project management as a way of managing, in formerly functionally structured organisations, is a complex process requiring strategic management intervention. The three outstanding issues contributing to this complexity are expounded. These are the differing characteristics of the range of an organisation's projects that must be provided for; the inherent characteristics of functional organisations inhibiting to a cross-functional approach. that need to be overcome; and the very necessary mind shift to the project management culture. that needs to be instilled. The ground rules for project management implementation is laid down by way of eight questions that must be answered on top management level. These revolve around a firm commitment to the replacement of old. seemingly well proven practices as well as around the implications and consequences for the organisations. The article then proceeds with proposing a framework for the process of project management implementation. This is presented in seven steps. concluding that the implementation should be approached as a project in own right. To that effect a generic work breakdown structure is offered as a guideline.
\end{abstract}

\section{Introduction}

From the plethora of available literature, project management can be described as being concemed with the achievement of complex goals, by integrating multifunctional inputs into a team relationship, under the guidance of a singular responsibility, authority and leadership. For the layman it might therefore appear that implementing project management in organisations is a simple matter of defining goals, assembling teams and appointing authoritative project leaders.

Research initiated by experience, however, dictates that implementing project management in formerly functional (bureaucratic?) organisations, that is transforming such organisations into project-driven or projectised organisations is mostly a complex process, requiring strategic management intervention. For example Nicholas (1990: 481) opines that project management represents a departure from traditional management and ' ... to most people project management represents a major change'. This clearly implies that organisations should not tread this path without a well-developed and organisation-fitted project management strategy (Krüger \& Steyn, 1995: 50, 61). As Nicholas (1990: 481) stated so aptly, 'Implementing project management is itself a project', for which a comprehensive implementation plan is needed.

The purpose of this article is threefold:

- Firstly to expound the issues contributing to the complexity of the process of transformation to project management.

- Secondly to expound the ground rules for the formulation of a strategy for implementing project management in organisations. This is done by way of posing eight questions, to be answered by top management.

- Thirdly to propose a framework for a generalised project management implementation plan.

The article is based on a literature study, practical experience over three decades and case studies of several South African organisations that had over the last two and a half years been engaged in transformation from functionally-driven to project-driven organisations.
The author was engaged in project management training to ca 500 officials of those organisations. amongst whom middle, senior and top management were reasonably well dispersed and coming from all over South Africa. It became clear from the outset that most of these officials were quite uneasy with the concepts as well as with the way management was trying to introduce and apply project management in their organisations. From informal discussions (and airing of many grievances) a formal research project based on interviews was conducted. The data and findings of that project form the basis of this article.

\section{Transforming to project management from a func- tional orientation is a complex process}

Three issues in particular have been identified in the literature, also borne out by experience, which separately and/ or jointly contribute to this complexity:

1. The projects of an organisation are seldom of a singular nature, but possess different characteristics (determinants) which can usually be portrayed on a continuum from simple to complex. By implication a continuum of managerial approaches, project management organisation styles and structures for the execution of the organisation's projects is mandated (Ford \& Randolph, 1992: 271, 272, 282). In fact, Sawle (1994: 8) quotes from a PMI publication Organizing for Project Management that 'the style of organisation used will have a major influence on the effectiveness, efficiency and success of the project effort'.

2. Various factors, which inhibit the application of project management principles, are always present to a greater or lesser extent in all functionally orientated organisations (Graham, 1994: 705).

3. The project management approach requires a mind shift to a greater or lesser degree, because it represents a different management culture. About this aspect Knutson (1994 437) says: 'Recognize that this is a significant -cultural change. The transition needs to be orchestrated and roles. accountabilities and authorities clearly defined and communicated' 
Each of the above issues has a marked effect on how project management will be exercised in an organisation and needs to be expounded to enable project management strategy formulation.

\section{Continuum of project management determinants}

Evidently the scope of a project will have a bearing on the extent of the specific management style required. For one of the organisations under investigation the possible range of determinants which was found to describe the range of the scope of its projects is shown in Figure 1.

The projects and the suitable project management approaches can now be classified along this continuum (see Figures 2 and 3).

\section{Factors that inhibit project management application}

Several factors that inhibit the introduction and application of project management into functional organisations have been identified:

1. Resistance to change, because the project structures, leadership styles, and information, planning and control system are departures from traditional management (Krüger et al. . 1995: 50).

2. Due to the diversity of project scope referred to before, acceptance of a singular (i.e. universal) project management methodology, will invariably lead to frustration and resistance from the project managers on smaller projects, who see it as too much extra work, not 'justified' for a smaller project.

3. Top management resists because additional management overhead is created as well as additional staff, mainly administrative, required (Kerzner, 1984; Ford et al., 1992: 276). The tendency of top management is therefore to keep people in their present posts and to just load the managing of projects onto their 'normal' functional workload. 'What could be a better strategy than to continue the style that's succeeded in the past?' (Tettemer, 1990).

4. People being driven by loyalty to their primary function, that is to first and foremost promote their professional, functional skills in a parochial sense. This leads typically to a 'prima donna' propensity that could mean being untouchable, inflexible and not inclined to share with others.

5. Absence of a 'team culture', that is failure to work together with and/or take orders from people outside one's own functional division.. This is particularly serious with highly skilled people and quite often manifests itself in the situation described in the previous point. In this regard
Ford et al. (1992: 282) observe that certain organisational cultures are more receptive to cross-functional structures than others. Organisational cultures characterized by rigid bureaucracy, minimal interdepartmental interaction, strong vertical reporting lines and little tradition of change, are not very receptive to cross-functional (project management) structures. In fact, unless the culture can be changed, resistance or open hostility to matrix may occur.

6. Low cost (money) and time sensitivity. Project manage ment is by definition concerned with performance, time and cost efficiency and consequently orientation to it is a success factor of critical importance (Kerzner, 1992).

7. The organisation structure. Most functional organisations do not provide for, or even facilitate non-functional management - the management of activities outside the jurisdiction of a function's hierarchy. This is, however, contradictory to the basic project management approach, namely that under project (or matrix) management, the project manager has primary control over the resources and the project's direction (Ford et al., 1992: 271). One characteristic of successful cross-functional teams is indeed that they are participative in nature and allow their members free and equal access to communication (Ford et al., 1992: 284); by implication then, outside of their own functional 'silo'.

8. Several factors pertaining to financial management were found to impede on effective project management implementation and functioning. Firstly a lack of or insufficient incentives to perform on any or all of the project management success factors (Graham, 1994: 706, 707). Secondly zero-based annual budgeting instead of continuous project budgeting; and thirdly a financial management system which does not include an autonomous activity- and output-orientated cost management system.

9. Occasionally statutory constraints may be inhibiting to project management, for example specific auditory requirements, the appointment of personnel and the actions of unions.

10. Invariably some of the organisation's undertakings will be inhibiting to the exercising of project management, due to the nature of their special characteristics. For example biological, medical, agricultural and developmental systems have been found in this research to be much more difficult to break down into deterministic work packages than typical engineering systems. The reason is that the work content, duration, resources to be applied and the outcome of actions cannot be forecasted to the same high level of cer-

$\begin{array}{ll}\text { Small (money) } & \rightarrow \text { Big } \\ \text { Short (time) } & \rightarrow \text { Long } \\ \text { Limited human resource needs } & \rightarrow \text { Extensive human resource needs } \\ \text { Simple } & \rightarrow \text { Complex } \\ \text { Single discipline } & \rightarrow \text { Inter-disciplinary } \\ \text { Goal is function-bound } & \rightarrow \text { Goal is not bound to a specific function } \\ \text { Low process involvement } & \rightarrow \text { High process involvement } \\ \text { Functional input predominant } & \rightarrow \text { Managerial input predominant } \\ \text { Pure scientist } & \rightarrow \text { Managerially skilled scientist } \\ \text { Input driven } & \rightarrow \text { Output driven } \\ \text { Prnject support } & \rightarrow \text { Project management }\end{array}$

Figure 1 Continuum of project determinants 
tainty than is the case with engineering, or even business systems. This is then usually put forward as a smoke screen to argue against and hinder attempts towards the implementation of project management. In the researchbased organisation investigated, the situation is further aggravated by the participants being mostly input (function) orientated rather than output (goal) orientated and being science or technically orientated without sufficient management inclination.

\section{Mind shift to project management}

Project management represents a completely different organisational and managerial culture from that of functional organisations.

Firstly a 'network' linking the various necessary inputs from different functions is superimposed on the conventional functional structure. The traditional functional hierarchy remains the comerstone of the organisation and project management is added as a secondary, temporary 'overlay' to deal with the organisational, co-ordinational and integrating complexities (Ford et al., 1992: 271). This has several implications for the organisation:

1. For the purposes and duration of the project the hierarchy of the functional structures is of very little consequence. The reason is that people occupying any hierarchical position and level may be an element of the project system under the direction of the project leader. He or she may in turn also come from any hierarchical position, even on a level subordinate to that of some of the elements. This proved to be the near death knell for project management in all the organisations under investigation.

2. For the functionaries (that is the team members) dual responsibilities, information flow and instruction taking result, both horizontally (transfunctional) towards the project manager and vertically (intrafunctional) towards the functional head.

3. The specific skill input of a functionary now becomes subordinate to and in support of the achievement of the project goal, and not a goal in its own right.

Secondly, functional heads usually regard the above as a threat to their authority and 'empire', because, 'the adjustment will reduce the functional manager's ability to control subordinates' activities' (Tettemer, 1992).

The line manager may also view the project manager as an obstacle to gain favorable exposure to top management and therefore a threat to future promotional opportunities. Perhaps the line manager considers the project manager unqualified to make decisions on specialized technical matters. Any or all of these things may impede willing co-operation by line managers. The sensitivity and importance of these new relationships cannot be overemphasized and need to be planned carefully and discussed thoroughly with managers at all levels before implementing project management (Easton \& Day, 1991).

The above reactions are, however, unnecessary and can successfully be put aside when their responsibilities are reoriented towards the creation, building and maintaining of functional skill capacity, instead of the management of its application. For them a shift from 'generalizing' towards 'specializing' takes place and they are in fact relieved of many cumbersome (for them) organisational and administrative tasks.

Thirdly, the project managers also feel threatened. They are often taken out of their functional skill area and thrust into a new area of activity with responsibilities for which they are most probably not adequately trained. In all probability the latter also does not provide the security of a career (Ford et al., 1992: 285). Efforts on their part to come to grips with project management are therefore viewed as fruitless and consequently meet with little enthusiasm.

Clearly the above matters need to be addressed if an organisation is considering projectising its activities.

Once the need for project management has been established, the organisation must be careful not to jump too precipitously into project management. It is risky for a chief executive to merely issue a memo creating a project and a project manager, and then expect everything to go well. This usually results in complete disruption of the entire organisation. Top management must realize that their management and their specialists very probably prefer the status quo. As indicated previously, line or functional management is very comfortable with the hierarchical organisation, and will be strongly resistant to change. It also must be recognized that the implementation of project management is a rather drastic change. Therefore, it must be carefully planned.

\section{Formulation of a project management strategy}

Tettemer (1991) asserts that the strategy should be devised such that it will allow the displacement of traditional relationships and practices with new ones while placing great emphasis on comforting top administrators during the period of change. This comforting should not only be about the validity of the outcomes of the projects, but above all with the validity of the project management process. To enable a strategy and an implementation plan for project management to be formulated, several questions pertaining to the matters discussed so far, need to be addressed:

1. The three primary questions:

1.1 What is the relative importance of the projects the organisation is contemplating? Are the projects part of the core business, as opposed to just facilitating support activities?

1.2 Does the organisation want to measure the process for achieving the results in addition to measuring only the results of its activities?

1.3 Is the top management firmly committed to the complex transformation process that lies ahead?:

- a willingness to perhaps replace practices which seemingly worked well for a long time with new ones;

- acceptance of short-term disruption of activities?; and

- commitment of resources and time (especially top management time) to see through a well devised game plan?

If the answer to the above is affirmative, then the organisation cannot afford not to transform, so as to facilitate project management and project management structures on a permanent basis

2. The five secondary questions:

2.1 Is the organisation open-minded enough to accept and adjust to a transfunctional and network culture? The choice of the first project and the first project manager is of the 
utmost importance. It might involve a considerable period of education and leaming. utilizing seminars and training sessions (Easton \& Day, 1991)

2.2 Will the necessary adaptation in the organisation structure be implemented? Exurafunctional management positions will need to be created and empowered vis-à-vis those of the functional managers, with the proper relationships to the laner. to top management and to the project customers.

2.3 Is the 'conventional' project management approach appropriate. or will a redefinition process to devise an organisation-specific methodology be necessary?

2.4 Is the organisation willing to implement the operational restnucturing which will be necessitated by a project management approach?:

- the financial management system will invariably need to be reformed to provide for activity-based costing and control;

- the performance evaluation/remuneration system will need to be adjusted. 'If project work is not part of the performance appraisal system, it will not be taken seriously' (Graham, 1994: 706);

- the post-level system will have to be reformed to allow for project manager posts and levels;

- data bases pertaining to project planning and informa- tion systems will have to be established; and

- a system for project manager evaluation taking cognizance of impact, performance. cost and time will have to be devised.

2.5 How much real autonomy is the organisation willing to bestow on its project managers? The answer must be considered in terms of four major implications for the orgafisation:

- the classification of projects with reference to a continuum will probably lead to classification of project leaders with the promise of evolutionary growth for the latter;

- empowerment of project leaders. Analogous to the previous reasoning, this must result in a continuum of project leader empowerment: and

- the establishment of a structured career path for project managers. The important considerations here are, what is the highest level to which a project manager can aspire; do project managers fit into the organisation's post-level structure?; should project managers be lifted out salary-wise?

It cannot be overemphasized that functionaries who become project managers have to contend with other skills and stresses than those in the areas from which they are

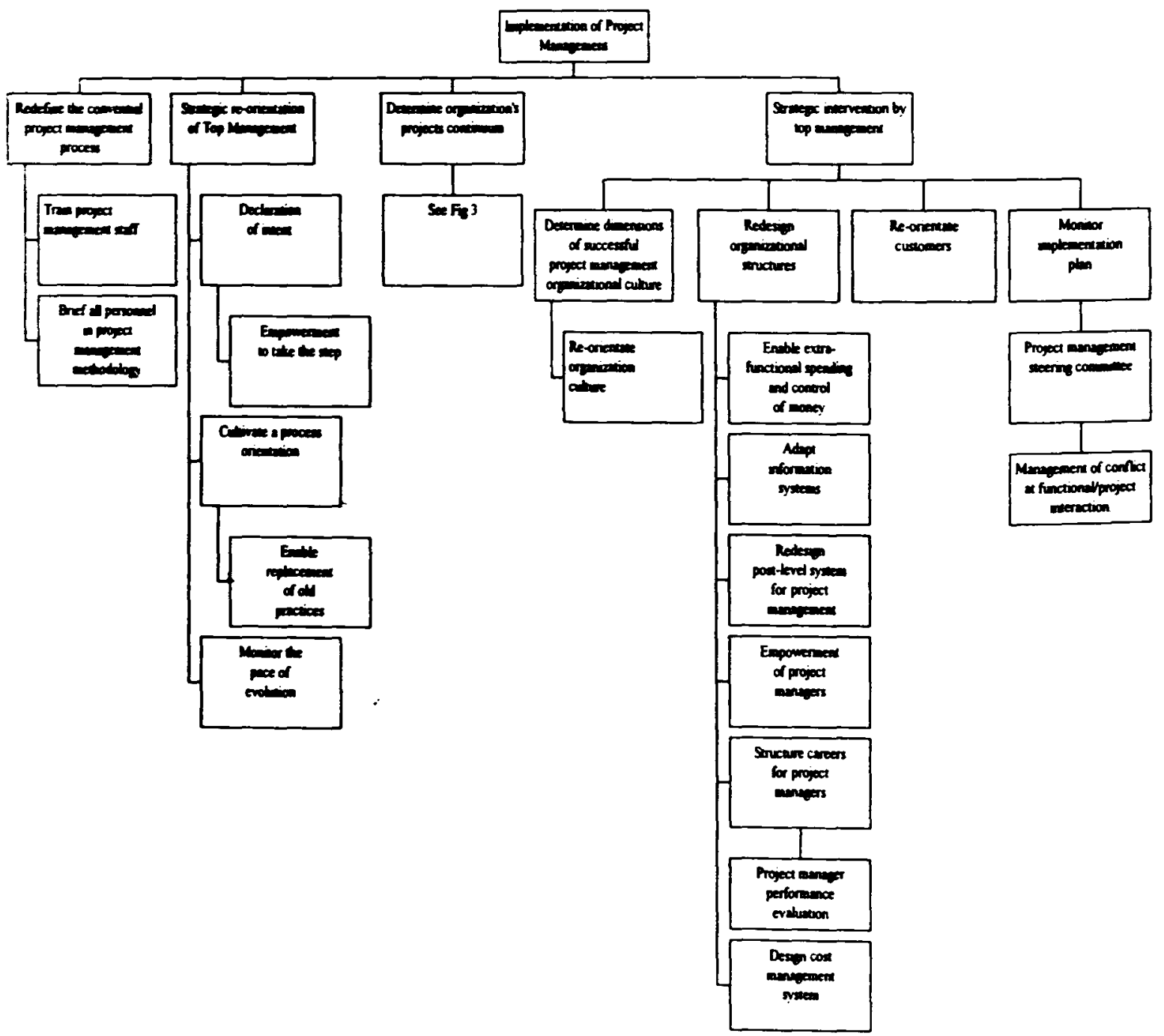

Figure 2 Work breakdown system (WBS) of project management implementation 
taken and that they, of necessity, need to contend with dual proficiencies, at least for the short term. Without a career path there is very little motivation to set foot on that path and the best managerial material will probably not be enticed into this field of endeavour. Accepting a continuum of projects and projects leaders, it is clear that the most exacting position of project manager is that on the right-hand side of the continuum. These people will not be readily available (if at all) without a developmental path from left to right through the continuum.

\section{A project management implementation plan}

'The first thing that must be done is to carefully plan the implementation process. It makes little difference whether this planning is done by top management, staff personnel, middle management or a consultant: a game plan for implementing project management is necessary' (Easton \& Day, 1991).

'Effective transitional management which entails prior planning, employee involvement and conflict resolution is needed when converting to a new project organisational structure' (Krüger et al., 1995: 61).

The second step is for top management to demonstrate its unequivocal support for a transition to the project management way of goal achievement (Easton \& Day, 1991; Krüger et al., 1995: 58). This needs to be communicated to the entire organisation by way of a clear and unambiguous declaration of intent (Graham, 1994: 706). The implementation of a new order of things is fraught with anxiety. Krüger et al. (1995: 63 ) has found the commitment, co-operation and participation of all key project participants to be a major success factor. And to obviate the anxiety, insecurity, uncertainty and unrealistic expectations, as well as to substantiate the commitment of the participants, the role of top management's public support and beliefs is beyond question (Graham, 1994: 706).

Project management by definition cuts across functional lines. Therefore the next step in the implementation plan is to establish a multi-functional project management steering committee. The function of this steering committee is the management and control of the design and implementation of the strategy as a project per se, and therefore to push for change, but not of a rate that in itself will build opposition (Tettemer, 1990).

The fourth step should be to determine the work breakdown structure (WBS) of this 'project'. As is always the case with drawing up a WBS, this is no mean or single-handed task, but requires a concerted, top-level team approach (Lanford \& McCann, 1983). The WBS for the development of a strategy towards project management implementation is shown in Figures 2 and 3.

Fifthly, the time scales need to be established so as to give the process a goal and meaning.

In the sixth step, the cost of the implementation process (for somé organisations even a conversion or transformation process) needs to be determined and managed.

In the last instance, as with any regular project, continuous evaluation which is the main task of the steering committee, is most important. After the decision to projectorise, the implementation thereof is not an obvious process. Especially in large organisations with different divisional cultures, the

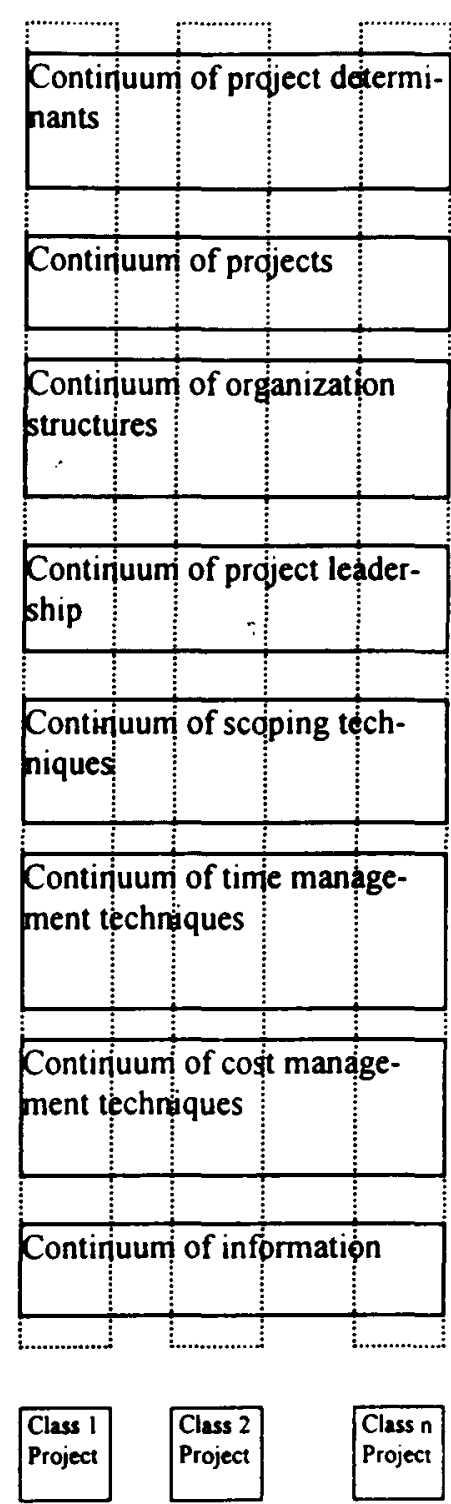

Figure 3 Continuum of project management scope

trust, experience, speed and acceptance of projectorising may differ markedly. It is also an experimental and evolutionary process, with organisations contemplating bigger and more complex projects in line with corporate growth. Exchange of experience and progress is an important source of information for the committee.

Experience has shown that this transformation up to full acceptance of the 'new' culture, smooth operation and a perceivable increase in effective project target achievement, can take from three to five years.

\section{Conclusion}

In many organisations the application of project management either fails dismally, or does not come off the ground effectively within reasonable time scales, nor with the type of favorable results that many textbooks claim. The main reason can be found in top management being enthusiastic, but not willing to face the implications and consequences for the organisation of introducing a project management system into their formerly bureaucratic organisations. Project management cannot simply be superimposed on an existing organisational structure without effecting its well being. To that effect 
the prerequisites for a successful project management implementation strategy was discussed. Based on providing for those prerequisites, an implementation plan and the framework for a strategy toward project management implementation, in the form of a WBS, has been developed. This WBS proved to be very successful as a guideline in the organisations investigated.

\section{References}

Ford, R.C. \& Randolph, W.A. 1992. Cross-functional structures: a review and integration of matrix organization and project management Journal of Management, 18(2): 267-294.

Graham. R.J. 1994. Leading the change to project management. Paper presented to the PMI 25 annual seminar, Vancouver. Canada, 17-19 October.

Easton, J.L. \& Day, R.L. 1991. Planning for project management, PMBOK. Drexel Hill, Pennsylvania: PMI.

Kerzner, H. 1992. Project management: a systems approach to planing. scheduling and controlling. $4^{\text {th }} \mathrm{ed}$. New York: Van Nostrand Reinhold.
Krüger, L.P. \& Steyn, G.P. 1995. The success factors in the implementation of project management in public sector works depart. ments, Management Dynamics. 4(4): 49-68

Knutson, J. 1994. The top management steering committee, Paper presented to the PMI $25^{\text {th }}$ annual seminar, Vancouver, Canada, 1719 October

Lanford, H.W. \& McCann, T.M. 1983. Effective planning and control of large projects using work breakdown structure, Long Range Planning, 16(2): 38-50

Nicholas, J.M. 1990. Managing business and engineering projects: concepts and implementation. Englewood Cliffs, New York: Prentice Hall.

Sawle, W.S. 1994. Leading projects in a functional environment: the functional project manager. Paper presented to the PMI $25^{\text {th }}$ annual seminar, Vancouver, Canada. 17-19 October.

Tettemer, J.M. 1991. Keeping your bosses happy while implementing project management - a management view, $P M B O K$. Drexel Hill, Pennsylvania: PMI 